$$
\begin{aligned}
& \text { بررسى يتانسيل قارج ريشهها و باكترىهاى سودوموناس در يالايش سبز } \\
& \text { كادميم از يك خاك آلوده } \\
& \text { ميرحسن رسولى صدقيانى "، حبيب خداورديلو، محسن برين و سولماز كاظم عليلو' }
\end{aligned}
$$

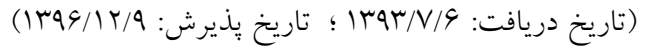

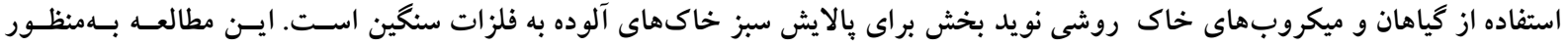

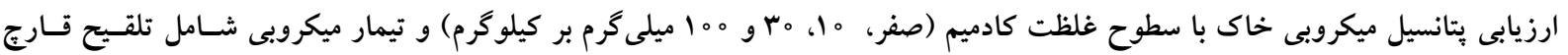

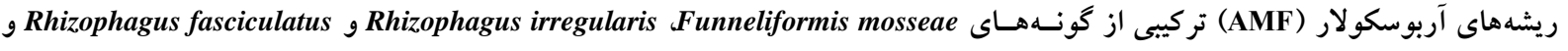

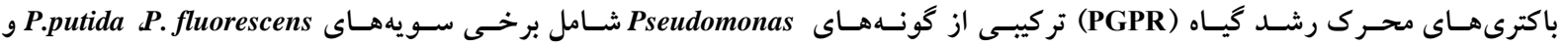
P. aeruginosa

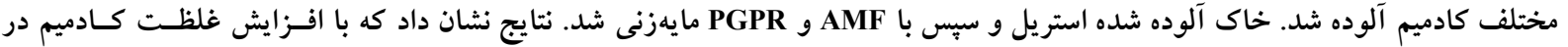

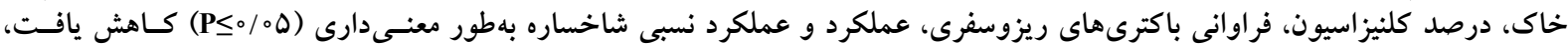

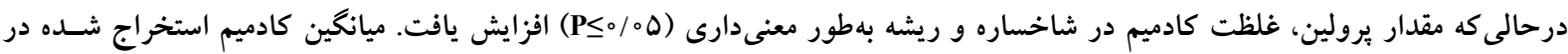

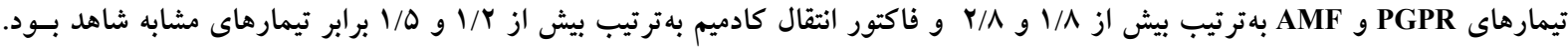

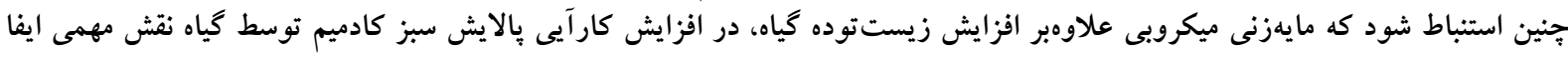

$$
\text { وازمهاى كليدى: پالايش سبز، گل كندم، كادميم، قارج ريشههاى آربوسكولار، باكترىهاى محرك رشد گياه }
$$


ميكروار كانيسمهاى خاك، قارج ريشهها ارتباط مستقيمى را بين خاك و

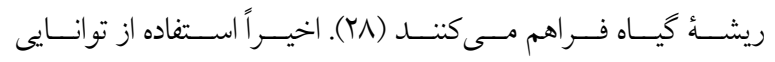

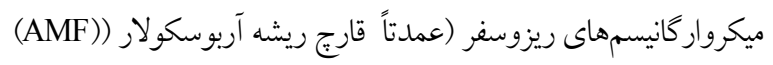
(Arbuscular Mycorrhiza Fungi

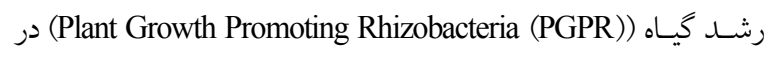

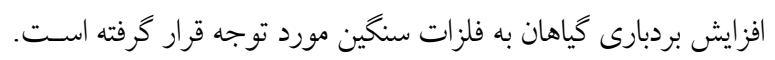

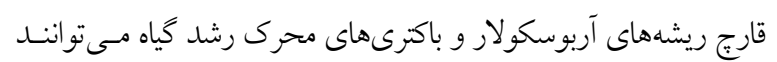

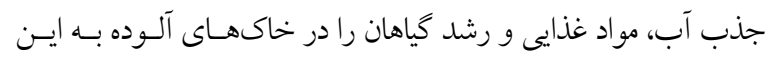

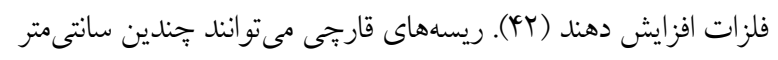

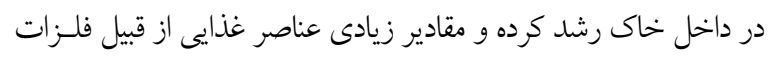

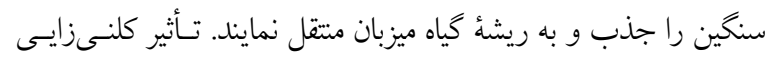

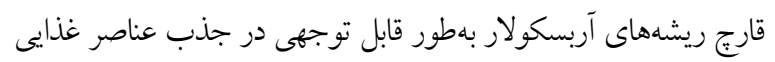

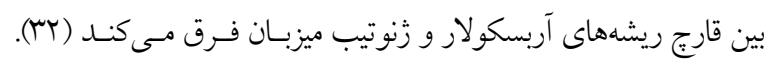

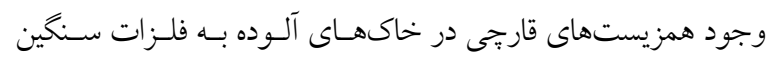
اهميت زيـادى در يـالايش ميكـوريزايى (Mycorrhizo-remediation)

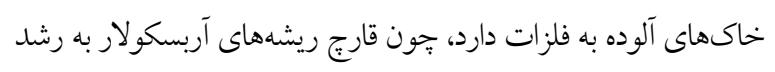

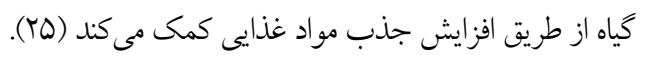

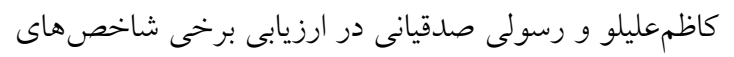

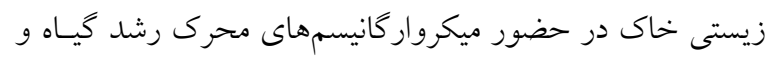

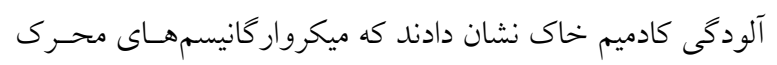

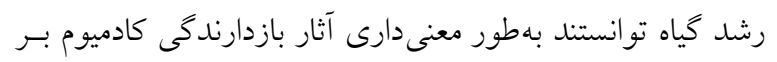

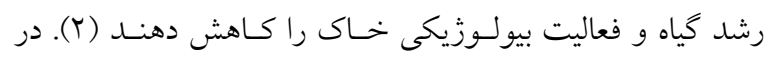
همين راستا شهابيوند و همكاران كزارش كردند كه حضور قـارج ريشه كلوموس موسه در غلظتهاى كـم كـادميم، كـادميم را در

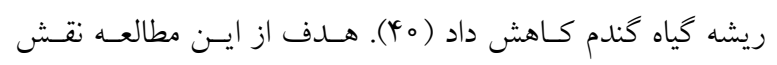

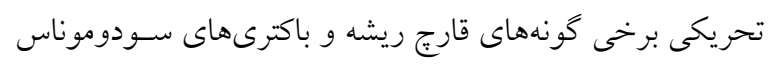

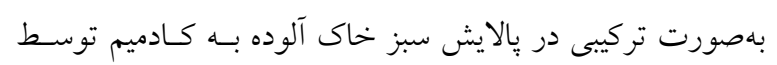
كياه گل گندم در شرايط گلخانه مورد بررسى قرار كرفت

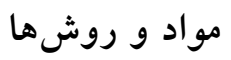
آمادهسازى خاى مورد مطالعه

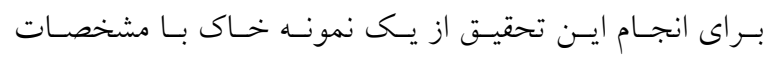

مقدمه در سالهاى اخير توجه به فلزات سنخين در خـاكهـا بـهدليـل

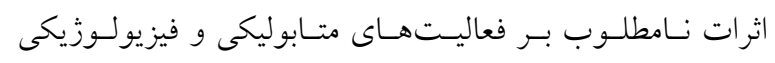

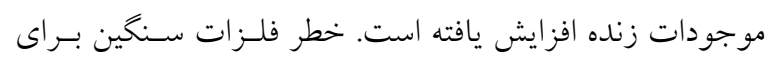

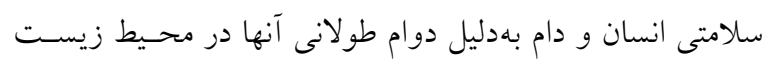

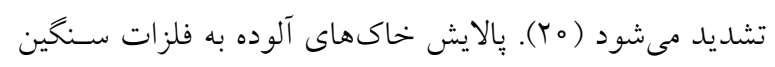

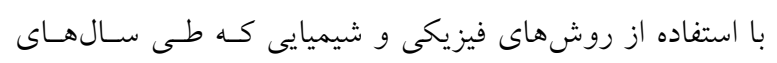
كذشته براى پاكسازى خاك مورد استفاده قـرار كرفتسه، بسـيار

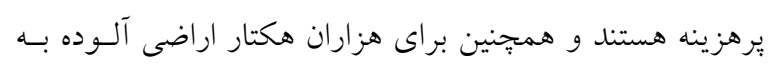

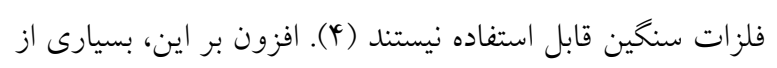

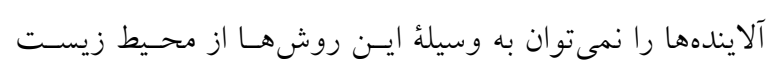

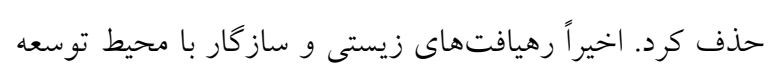

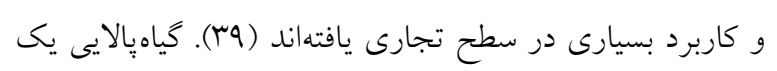

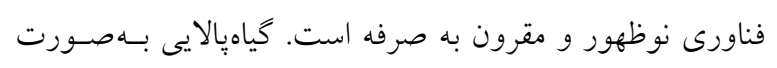

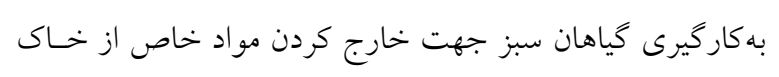

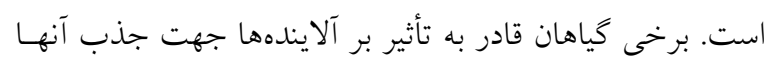
به درون سيستم آوندى خود هستيند و برخسى ديخـر، تركيبـات

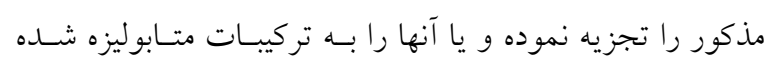

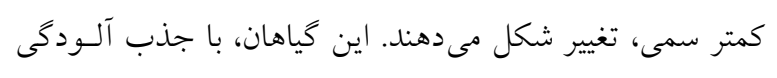

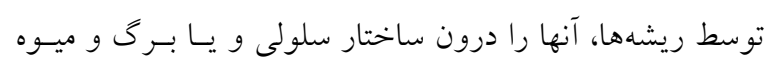

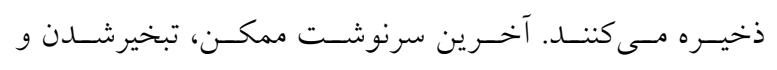

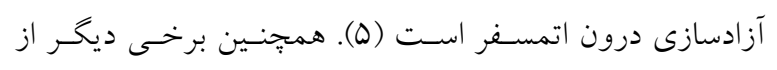

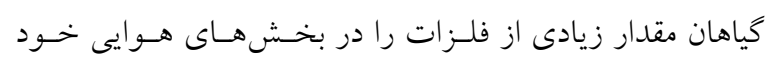

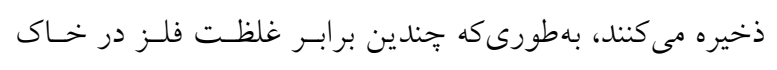

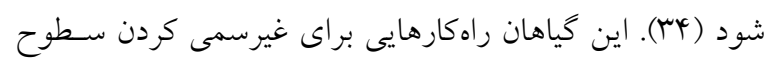

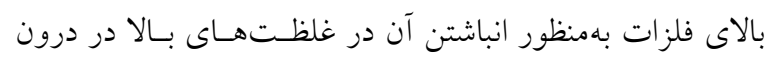

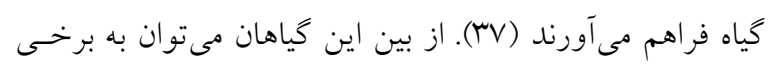

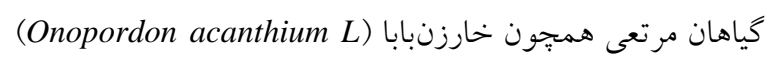

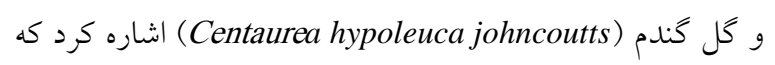

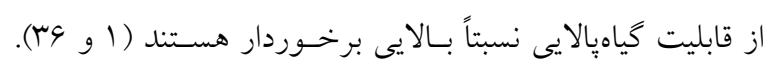

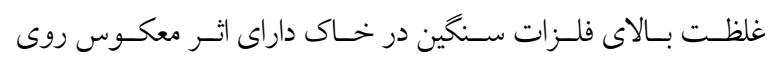

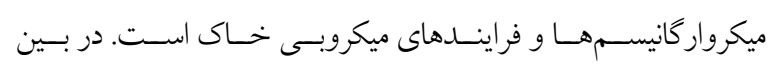


درجه سانتى گراد و فشار 1/ه بار در داخل كيسههاى كنفى استريل

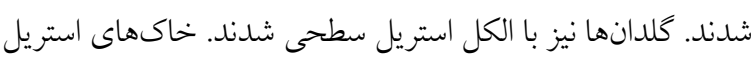

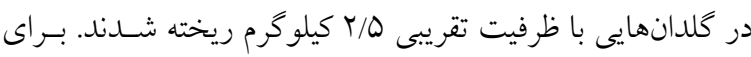

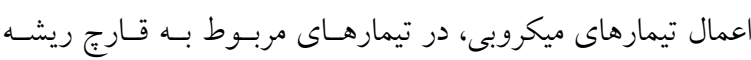

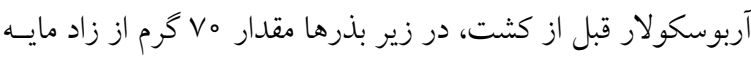
بلهورت لايهاى به ضخامت تقريبى دو سانتىمتر اضافه شد. تيمار

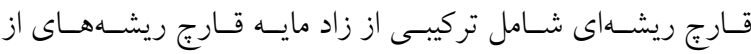
كونهاى Rhizophagus irregularis، Funneliformis mosseae Rhizophagus fasciculatus بودند. تعداد كل اسـيورهاى قـاريىى

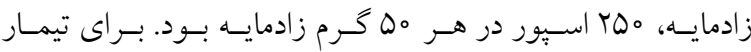

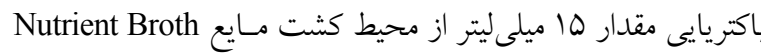

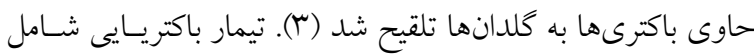

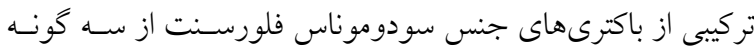

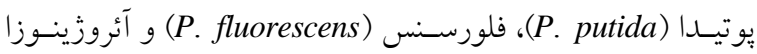
بود كه بهمدت ^^ץ سـاعت در دمـاى ^ץ درجسه

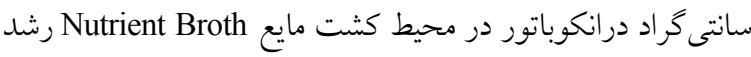
كرده بودند. جمعيت اين باكترىها حدود بود. پِ از اعمال تيمارها كشت گياهان انجام شد.

\section{كشت گیاهان و مراحل داشت}

يّ از رساندن رطوبت كلدانهـا بـهـ ظرفيـت زراعى و اعمـال تيمارها در هر كُلدان 9 تا 1 بذر (ضدعفونى سطحى شده) كيـاه

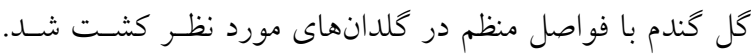

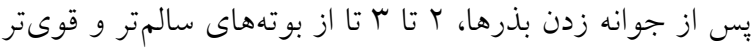

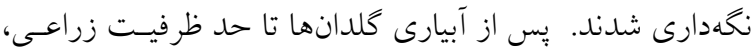
وزن هر كلدان بر روى آن يادداشت شد تا در مر احل بعدى از هر

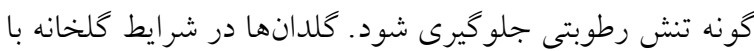

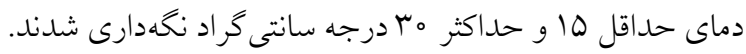

\section{برداشت گياهان و اندازهيرى ويزگىها} در بايان ماه ينجم رشد، بخش هوايى كياهان از رويه خاك بر يــده

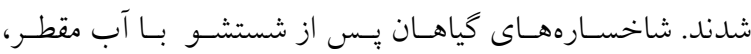

Fine, mixed, mesic Typic Halaquepts

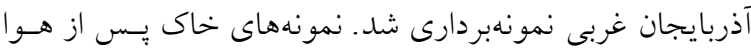

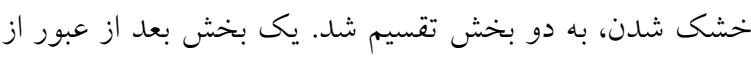

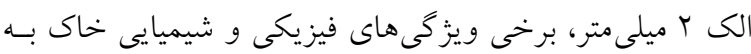

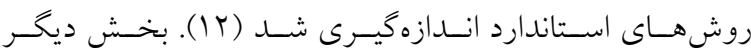

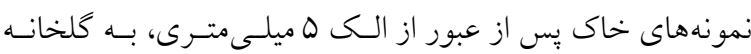

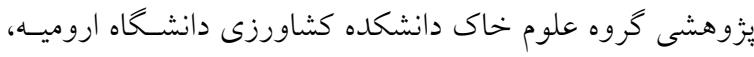

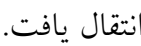

\section{آلوده كردن خاك مورد مطالعه}

براى آلوده كردن خاى، غلظت آلاينده با توجه به حدود هدود غلظت

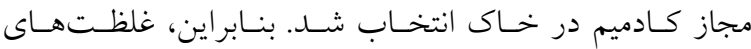

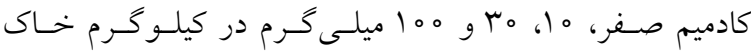

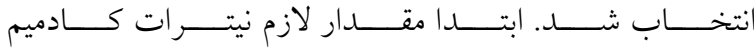

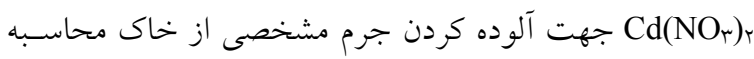

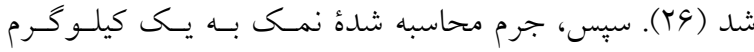

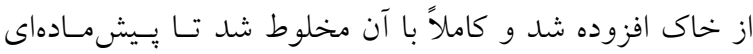

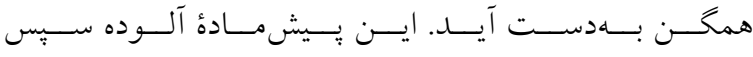
بهطور كامل با توده خاك مخلوط شد. سبس خاكهـاى آلـوده

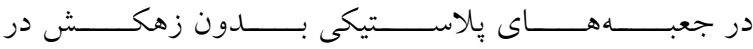
معرض دورههاى متناوب تر و خشك شدن قرار كرفتند. در هر

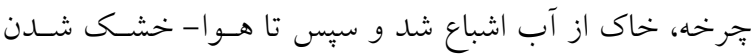
در دماى اتاق ماند. خاكها در جهار جرخه به همين روش تـر و خشك شدند كه هر جرخه حدود مثا روز به طـول انجاميـد كه تا حد امكان برهمكنشهاى آلاينده و خاك تكوين يافتسه و

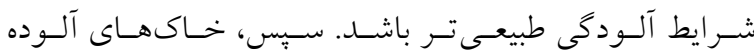

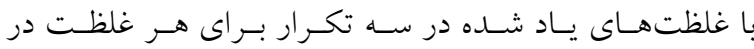

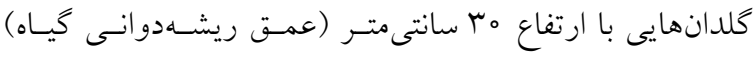

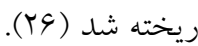

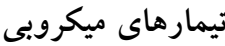

نمونههاى خاك آلوده شده در اتو كلاو در دو نوبت در دمـاى اليقاى 


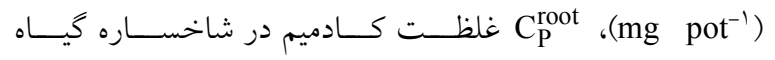

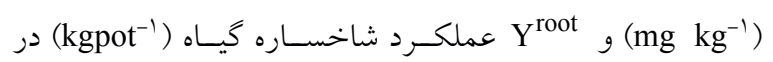
سطوح مختلف آلودكى است. $\mathrm{BCF}=\frac{\mathrm{C}_{\mathrm{P}}}{\mathrm{C}_{\mathrm{S}}}$

كه BCF، ضريب تغليظ زيستى براى ”ِـالايش سطوح مختلـف كآل

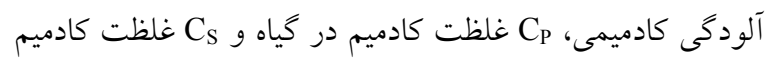
در خاك است. هرجه اين ضريب بيشتر از يك باشد، به معنساى تجمع بيشتر آلودخى خاى توسط كياه است. $\mathrm{TF}=\frac{\mathrm{C}_{\mathrm{P}}^{\text {Shoot }}}{\mathrm{C}_{\mathrm{P}}^{\text {root }}}$

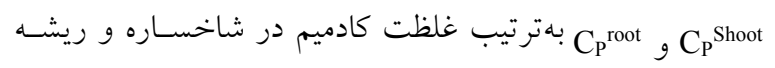
كياه و TF فاكتور انتقال كادميم از ريشه به شاخساره است.

\section{تجزيه آمارى دادهها}

آزمايش بلصورت فاكتوريل بادو فاكتور غلظت كادميم (در جهار

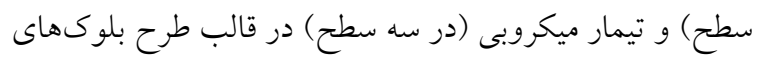

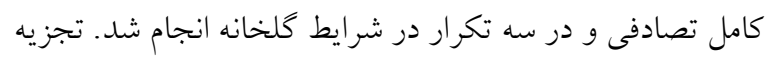

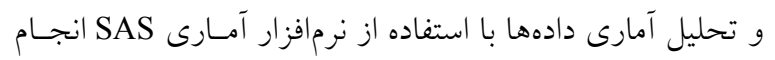

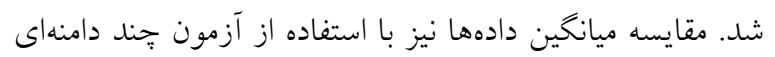
دانكن و در سطح احتمال ينج درصد انجام شد.

\section{نتايج و بحث}

نتايج برخى ويزگكىهاى فيزيكى و شيميايى خـاك مـورد مطالعـه

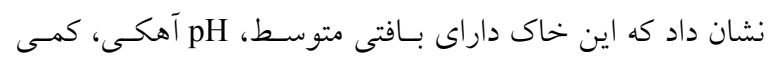

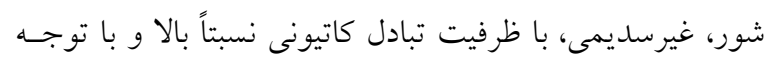

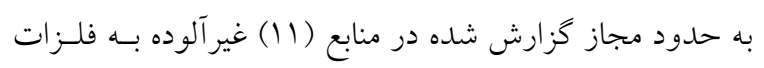
سنخين بود (جدول 1).

\section{فراوانى باكترىهاى ريزوسفرى}

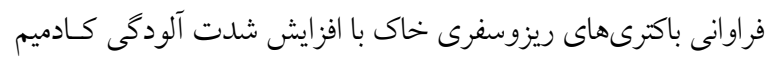

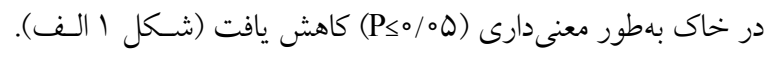

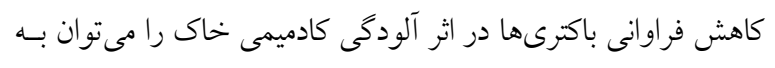

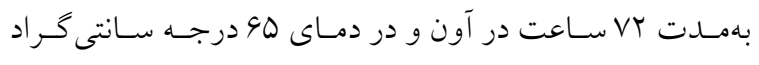

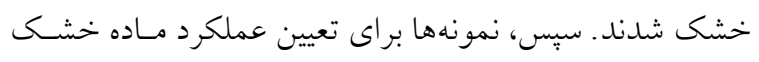

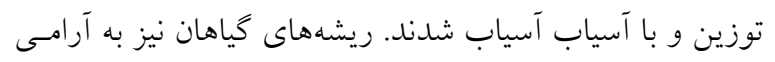

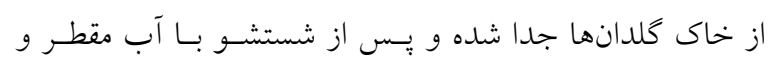

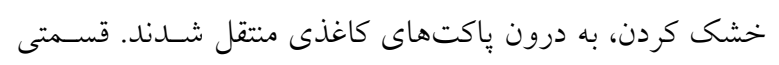

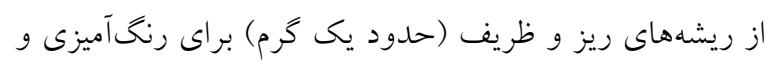

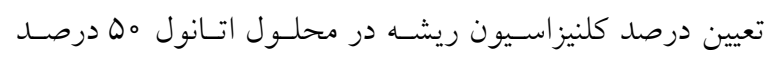

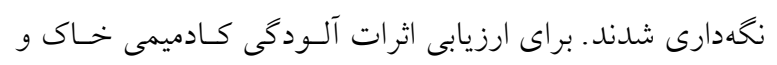

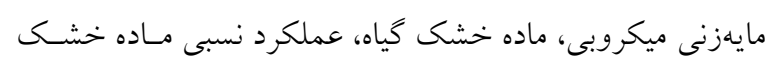
شاخساره آن نيز بهصورت زير محاسبه شد: ماده

$R Y=\frac{Y_{i}}{Y_{0}}$

كه در آن RY عملكرد نسبى گياه ، Yi عملكرد ماده خشك گياه در هر تيمار و و عملكرد ماده خشك كياه در شرايط بدون كادميم و

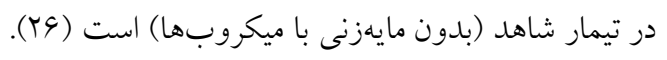

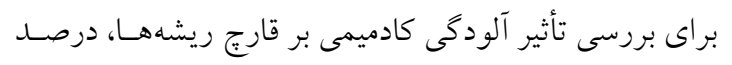

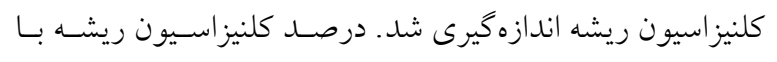

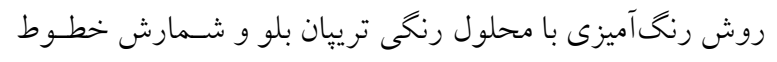

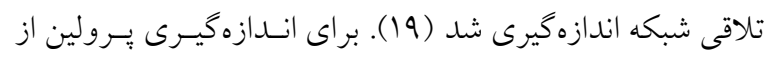

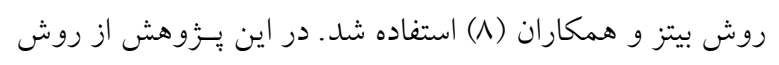

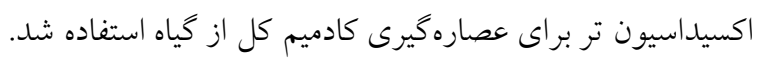

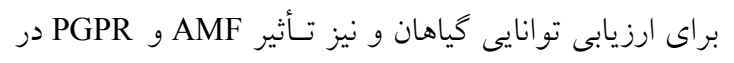

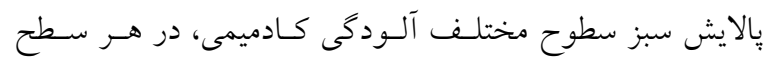

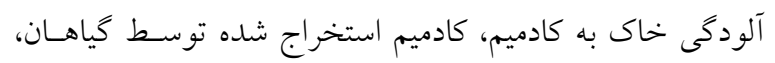

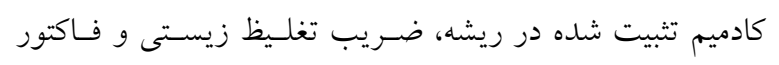

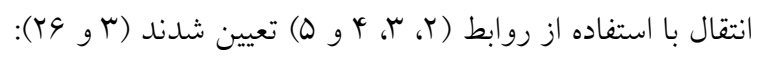
$\mathrm{ME}=\mathrm{C}_{\mathrm{P}}^{\text {Shoot }} \times \mathrm{Y}^{\text {Shoot }}$ كه در آن ME كادميم استخراج شده توسط شاخسـاره كياهـان

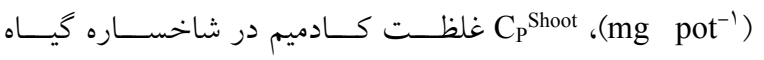

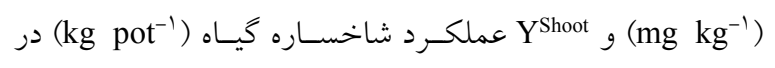
سطوح مختلف آلودگى است. $\mathrm{MS}=\mathrm{C}_{\mathrm{P}}^{\text {root }} \times \mathrm{Y}^{\text {root }}$ كه در آن MS كادميم استخراج شده توسط شاخسـاره كياهـان 
جدول ا. برخى ويزگى هاى فيزيكى و شيميايى اوليه خاى مورد مطالعه

\begin{tabular}{|c|c|c|c|}
\hline مقدار & 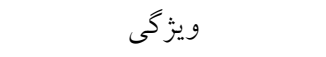 & مقدار & ويز كى \\
\hline$r M / \Lambda$ & سديم محلول (mg L & M & شن ( \\
\hline$\circ / \circ$ & يتاسيم محلول (mg L') & $r \circ r$ & سيلت ( \\
\hline$\circ / \wedge$ & كربنات محلول (mg L') & rVY & رس ( \\
\hline $0 / 9$ & بىكربنات محلول (mg L') & 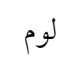 & كلاس بافتى خاى \\
\hline $10 / Y$ & كلر محلول (mg L') & $r \& / 9$ & مواد آلى ( \\
\hline r/凡 & سولفات محلول (mg L') & $r r / l$ & $\left(\mathrm{cmol}_{\mathrm{c}} \mathrm{kg}^{-1}\right) \mathrm{CEC}$ \\
\hline TI/AT & كل سرب (mg kg-1) & $T / Q$ & $\left(\mathrm{dS} \mathrm{m}^{-1}\right) \mathrm{ECe}$ \\
\hline $1 / 4 V$ & كل كادميم (mg kg & r & (\%) ESP \\
\hline$r 90 / 0$ & كل آهن (mg kg & $r \circ / 0$ & $(\%) \mathrm{CCE}$ \\
\hline ar & كل روى (mg kg-1) & $\Lambda / 1$ & $\mathrm{pH}$ \\
\hline \multirow[t]{2}{*}{$\mid 4 / 11$} & كل مس (mg kg & $1 / r$ & كلسيم محلول (mg L \\
\hline & & $\circ / 4$ & منيزيم محلول (mg L \\
\hline
\end{tabular}

CEC

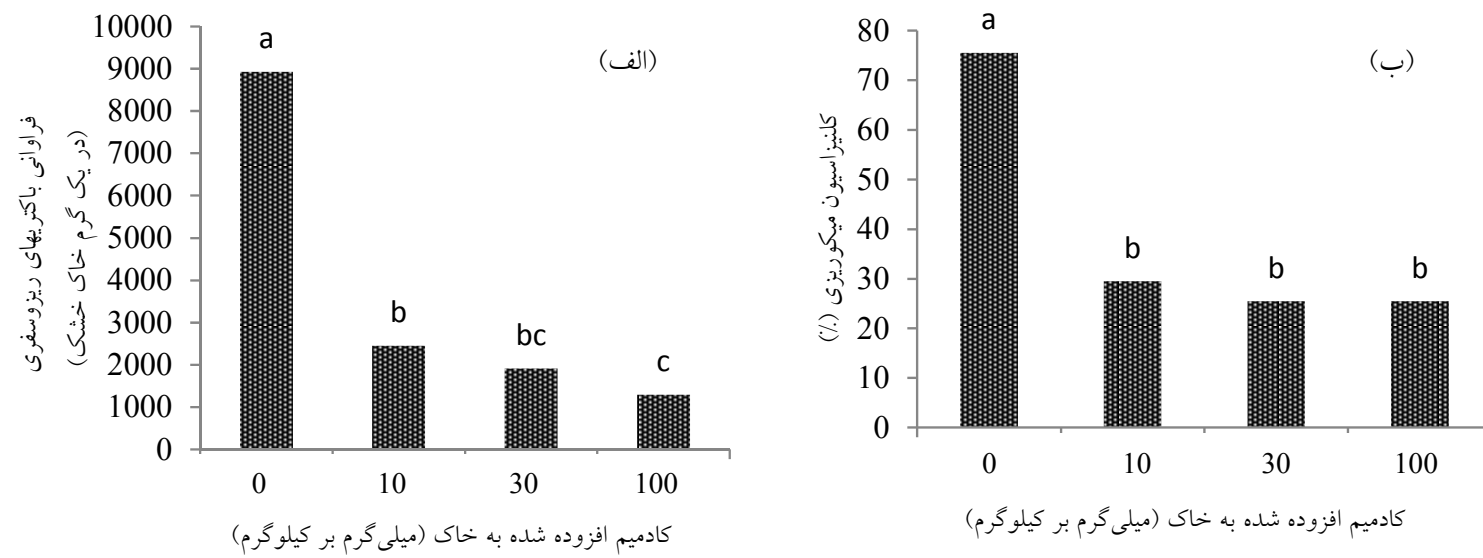

شكل (. الف) فراوانى باكترىهاى ريزوسفرى و ب) درصد كلنيزاسيون ميكوريزى ريشه در سطوح مختلف كادميم در خاك

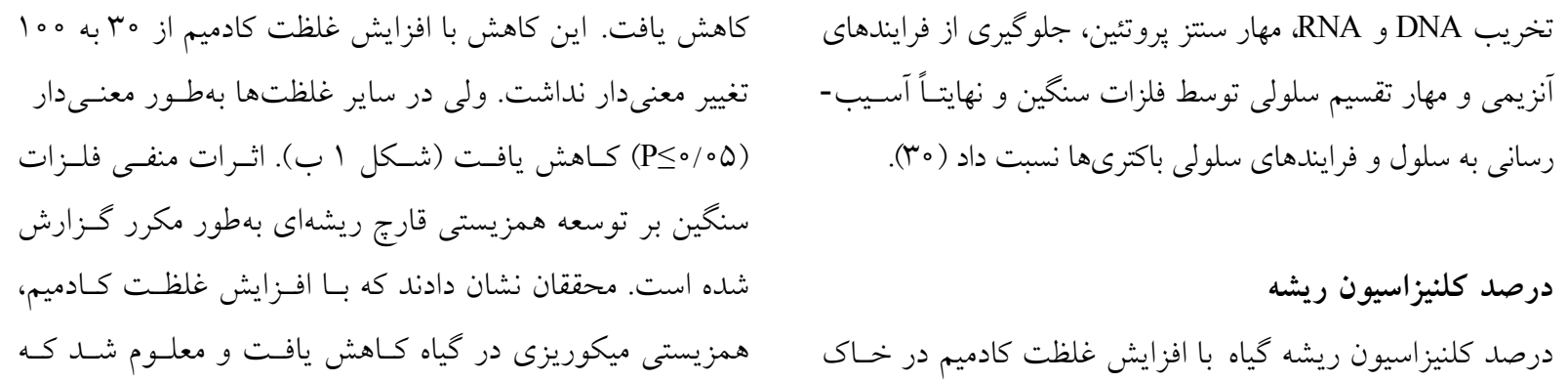


نشريه علوم آب و خاك (علوم و فنون كشاورزى و منابع طبيعى) / سال بيست و دو / شماره يك/ بهار IrqV

جدول Y. مقايسه ميانخين ويزٔى هاى فيزيولوزيكى گياه در سطوح مختلف كادميم در خاك در تيمارهاى شاهد، PGPR و AMF

\begin{tabular}{|c|c|c|c|}
\hline AMF & PGPR & شاهد & \multirow{2}{*}{ كل كادميم افزوده شده به } \\
\hline \multicolumn{3}{|c|}{ عملكرد شاخساره( } & \\
\hline $1 / 4 \Delta \pm \circ / \Delta \circ a, a$ & $1 / \Gamma \Delta \pm \circ / T q^{a, a}$ & $\circ / \Lambda V \pm \circ / / q^{\mathrm{b}, \mathrm{a}}$ & $\circ$ \\
\hline$\circ / 9 ৭ \pm \circ / \circ \diamond^{\mathrm{a}, \mathrm{ab}}$ & $\circ / \Delta \mu^{\mu} \pm / \circ \mu^{b, b}$ & $\circ / \Delta r \pm \circ / \circ q b, b$ & 10 \\
\hline$\circ / 09 \pm \circ / \circ V^{a}, b c$ & $\circ / T \Delta \pm \circ / \circ Y^{b, b}$ & $\circ / 19 \pm 0 / 0 r^{b, c}$ & r。 \\
\hline$\circ / 4 \circ \pm \circ / \circ \varphi^{a}, \mathrm{c}$ & $\circ / T \Delta \pm \circ / \circ \varphi^{c b, b}$ & $\circ / \circ ৭ \pm \circ /\left.\circ\right|^{c, c}$ & 100 \\
\hline \multicolumn{4}{|c|}{ عملكرد نسبى شاخساره گياه(g pot } \\
\hline $1 / 94 \pm 0 / 1 q^{a, a}$ & $1 / \Delta \Delta \pm \circ / \circ \wedge^{\mathrm{a}, \mathrm{a}}$ & 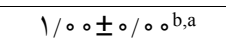 & $\circ$ \\
\hline $1 / \Lambda \Lambda \pm \circ / Y V^{\mathrm{a}, \mathrm{b}}$ & $0 / 9 \pm 0 / / 1^{\mathrm{b}, \mathrm{b}}$ & $0 / 9 Y \pm 0 / 19^{b, b}$ & 10 \\
\hline$\circ / \mathrm{V} \circ \pm \circ / \mathrm{Y}_{\circ}^{\mathrm{a}, \mathrm{c}}$ & $\circ / \Gamma \circ \pm \circ / \circ c^{b, b}$ & $\circ / 19 \pm 0 / 0 q^{b, c}$ & r。 \\
\hline$\circ / \mathbb{f} V \pm \circ / \circ \varphi^{\mathrm{a}, \mathrm{c}}$ & $\circ / q^{\prime} \pm \circ / \circ q^{b, b}$ & $\circ / 1 \circ \pm \circ / \circ \mu^{c, c}$ & 100 \\
\hline \multicolumn{4}{|c|}{ يرولين ( } \\
\hline $991 / \Gamma \pm V / / \Delta^{\mathrm{a}, \mathrm{d}}$ & $q \Delta r / \Delta \pm r \circ \circ / q^{a, d}$ & $V \circ \mid / V \pm I V Y / \wedge^{a, c}$ & $\circ$ \\
\hline $\mid Q V Y / \circ \pm Y \& Y \% /{ }^{b}, c$ & $\mu V V V / r \pm r q \Lambda / \circ a, c$ & $\varphi \psi \circ V / \varphi \pm V / V / q a, b$ & 10 \\
\hline$r \varphi \Delta s / T^{\mu} \pm \mid \Lambda \circ / \Lambda^{c, b}$ & $\Lambda r^{\prime} V / \circ \pm I r r / q^{a, b}$ & $\Delta \& q \psi / q \pm q \mu / \Delta^{b, a b}$ & r。 \\
\hline$r V \Delta \circ / \circ \pm q \psi_{\circ} / \mu^{c, a}$ & $10099 / V \pm r \wedge r q / q^{a, a}$ & $q \Lambda \circ Y / \mu \pm \mid r \Lambda / Y^{\mathrm{b}, \mathrm{a}}$ & 100 \\
\hline و & لاف آمارى در سط & 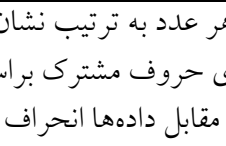 & 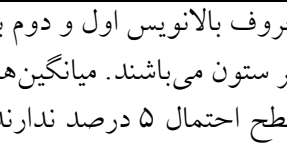 \\
\hline
\end{tabular}

عملكرد و عملكرد نسبى ماده خشك شاخساره

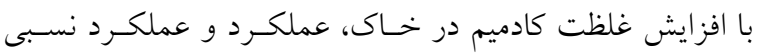

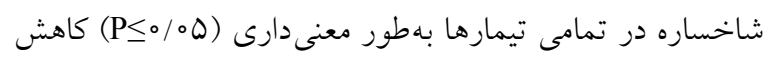
يافت (جـدول r). در هـر سـطح از غلظـت كـادميم در خــاك، مقادير مادهشك شاخساره در تيمارهاى AMF و PGPR بهطور

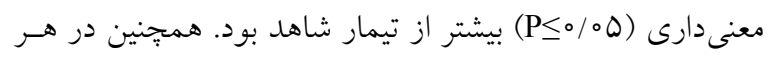
سطح از غلظت كادميم در خاك، مقادير ماده خشـك شاخسـاره در تيمار AMF بيشتر از تيمار PGPR بود.

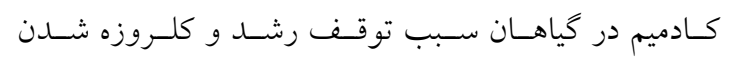
برگهاى كياهان، كاهش و توقف رشــ ريشـه، افـزايش توليـد اتيلن در كياه و ببهويزه اندوزش آن در ريشه، جوبِ بنبهاى شدن و صدمه به ساختمان خارجى و داخلمى ريشـه، كـاهش هــايت هيدروليكى آب در ريشه مى شود. همجهنين سـميت كـادميم بـر فرايندهاى اصلى كياه نظير فتوسنتز، تكثير سلولى و جـذبـ آب آب

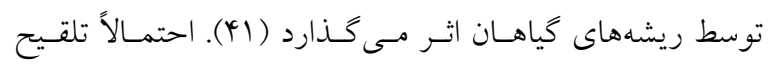
باكترىهاى محرى رشد كياه توليد اتيلن ناشى از تـنش فلـزات
سطوح بالاى فلزات سنخين در خاك، همزيستى ميكـوريزى را به شدت كاهش ميدهد (10). مقدار برولين در شاخساره با افزايش غلظت كادميم در خاك مقدار يسرولين در همسـُ تيمارهـا

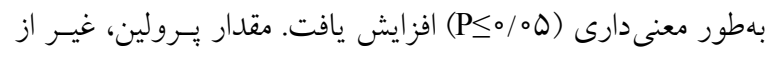
غلظت صفر در تمامى سطوح كادميم در PGPR بيشتر از شـاهد و AMF بود كه دليل اين امر را مىتوان به بالا بودن غلظت كادميم در

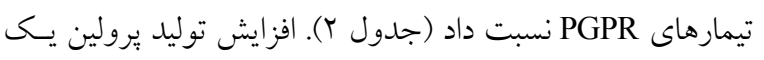
مكانيسم ساز گارى به تنشهـاى محيطى اسـت (YIY). يـرولين در كياهان تحت شرايط نامناسب رشد، از جمله تنش فلـزات سـنخين

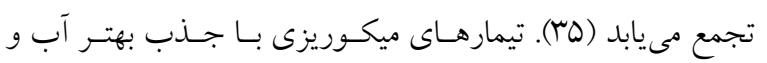
عناصر غذايى احتمالاً كمتر تحت تنش بوده به همين دليـل مقـدار يرولين نيز يايينتر است. يرولين بهعنوان يك اسـمولايت مهـم در تعديل فشار اسمزى سلول تحت تنشهاى فلزات سـنخين، دمـاى يايين، كمبود مواد غذايى و اسيديته بالا نقش دارد (سMو (IV). 
بررسى بتانسيل قارج ريشهها و باكترىهاى سودوموناس در پالايش سبز...

جدول r. مقايسه ميانگين مقادير غلظت كادميم شاخساره، كادميم استخراج شده و غلظت كادميم در ريشه گياه در سطوح مختلف

كادميم در خاك در تيمارهاى شاهد، PGPR و

\begin{tabular}{|c|c|c|c|}
\hline $\mathrm{AMF}$ & PGPR & شاهد & \multirow{2}{*}{ كل كادميم افزوده شده به } \\
\hline \multicolumn{3}{|c|}{ غلظت كادميم شاخساره گياه ( } & \\
\hline$Y Y / G \pm Y b, c$ & $\Delta \varphi / \mathcal{f} \pm\left.\right|^{\mathrm{a}, \mathrm{d}}$ & $\Delta \circ / \uparrow \pm \mid a b, c$ & $\circ$ \\
\hline$V \mid V / q \pm \psi^{c} \wedge^{\mathrm{a}, \mathrm{b}}$ & $\vee 90 / 0 \pm 19 \wedge^{\mathrm{a}, \mathrm{c}}$ & $\uparrow \wedge \mathrm{Q} / \circ \pm \vee \wedge^{\mathrm{b}, \mathrm{b}}$ & 10 \\
\hline$\Lambda \circ \Delta / \vee \pm q \varphi^{b, b}$ & $|r T \Delta / \circ \pm| V^{a, b}$ & $q \leftrightarrow \mu / \Lambda \pm \wedge q^{a b, a}$ & r。 \\
\hline $1 \circ \varphi \vee / \mu \pm \mid \wedge \gamma^{b, a}$ & $19 r q / 9 \pm \psi r v a, a$ & - & 100 \\
\hline \multicolumn{4}{|c|}{ كادميم استخراج شده توسط گياه ('mg pot } \\
\hline$G \circ / V \pm \mid Q / q^{a, c}$ & $9 \mathrm{~V} / \mathrm{V} \pm 1 \circ / \mathrm{r}_{\mathrm{a}, \mathrm{c}}$ & $r \wedge / r^{\prime} \pm r / q^{b, c}$ & $\circ$ \\
\hline$V Y Y / \circ \pm \mid V / q^{a, a}$ & $r \Delta r / q \pm r q / 4 b, b$ & $Y \varphi Q / \Lambda \pm \backslash \Lambda / T^{b, a}$ & 10 \\
\hline 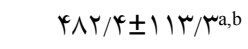 & & $10 r / q \pm \psi^{q} V / \Gamma^{b, b}$ & $\mu_{0}$ \\
\hline$\psi \backslash V / \Delta \pm \psi r / Y^{a}, b$ & $\not \psi|l| q \pm 1 \circ / D^{\mathrm{a}, \mathrm{a}}$ & - & 100 \\
\hline \multicolumn{4}{|c|}{ غلظت كادميم در ريشه ( } \\
\hline$\circ / \Lambda \mathrm{r} \pm \circ / /^{\mathrm{b}, \mathrm{d}}$ & $1 / \Delta Y \pm \circ /\left.\circ\right|^{\mathrm{a}, \mathrm{d}}$ & $1 / \mathrm{V} \circ \pm \circ / Y^{\mathrm{a}, \mathrm{c}}$ & 。 \\
\hline$V Y / \Delta \Delta \pm Y^{c b, c}$ & $\Lambda V / \Lambda \uparrow \pm \Lambda^{\mathrm{a}, \mathrm{c}}$ & $\Delta \mathrm{V} / \circ \circ \pm \mathrm{V}^{\mathrm{c}, \mathrm{b}}$ & 10 \\
\hline $110 / 9 \circ \pm y^{c b, b}$ & $\mid r \mu / 4 \varphi \pm \Delta^{\mathrm{a}, \mathrm{b}}$ & $৭ \wedge / \vee \varsigma \pm \vee^{c, a}$ & $r_{0}$ \\
\hline $1 \Lambda \Lambda / \circ \Delta \pm \mu^{b, a}$ & $r \varphi \Delta / 4 \Lambda \pm \Lambda^{\mathrm{a}, \mathrm{a}}$ & $|r y / \Delta \varphi \pm| \circ c, a$ & 100 \\
\hline \multicolumn{4}{|c|}{ 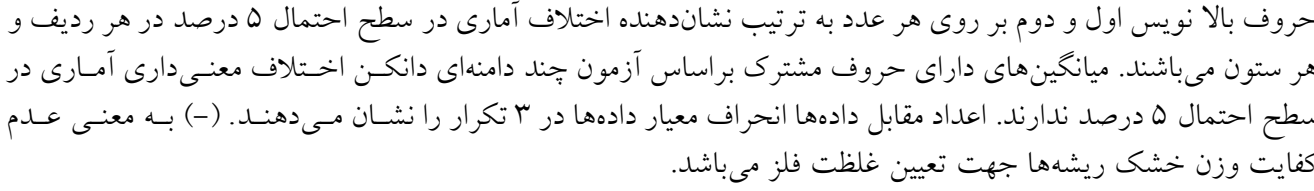 } \\
\hline
\end{tabular}

غلظت كادميم و مقدار كادميم استخراج شده توسط شاخساره با افزايش غلظت كادميم در خاك، غلظت كـادميم در شاخسـاره

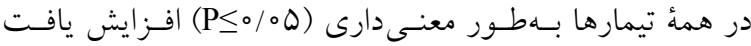
(جدول ץ). غلظت كـادميم در شاخسـاره در تيمـار PGPR در همه سطوح كادميم در خـاك، بيشـتر از تيمـار AMF بـود. نـوع (a. جمعيت ميكروبى (قارج ريشهها و PهPR)، غلظت فلـزات و نوع گياه مىتوانند تأثير اتى متفاوت بــر جـــب و انتفـال فلـزات

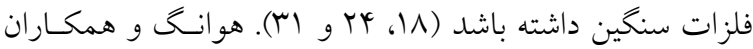
(Yl) سنخين توسط ذرت بيان كردند كه قارج ريشههـا مسى توانـــ از كياهان عالى در مقابل سميت و غلظت بيش از حد مس، روى و سرب به كمك تغيير شكل دادن آنها از فرم قابل دسترس به فرم غيرقابل دسترس محفاظت كنند. در واقع تجمع مسس و روى در

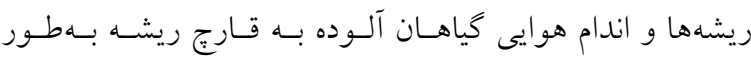

سنخين در گياه را كاهش داده (باكترىهاى مانند سودوموناسها حاوى آنزيم تجزيه كننده يــش ســاز اتسيلن (ACC)) و موجسب افزايش زيستتوده گياهى و ارتفاع گياه مىشود (9). همجنين با توليد سيدروفورهاى ميكروبى و تركيبات متابوليت، مىتوانند در دستيابى به هدف مورد نظر كه همان افـزايش توليــ و وبـالايش آلايندهاست، بسيار مفيد باشند. همجنين در منابع گزارش شده است قارج ريشههاى آربوسكولار بـهـدليـل داشـتن شـبكهاى از هيف ها مىتوانند جذب عناصر غذايى بهويسزّه فسـفر راتوسط كياه افزايش دهند كه در نتيجــه آن بـا بهبـود شــايط تغذيسهاى كياه، وزن خشك اندامهاى هو ايى و برخى از يارامترهـاى رشــ

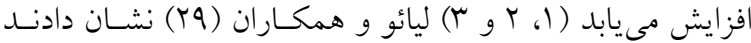
كه تلقيح ميكوريزى با افزايش سطوح كـادميم در خـاك سـبب افزايش ماده خشكى ريشـه گيـاه در مقايسـه بـا كياهـان شـاهد 


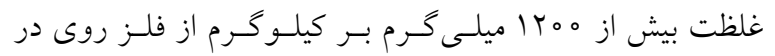

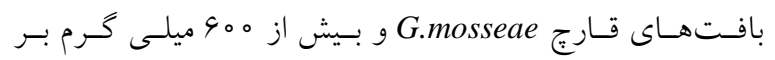
كيلو گرم در بافتهاى قارج

ضريب تغليظ زيستى شاخساره و ريشه (BCF)

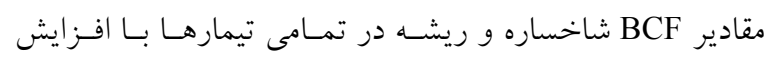

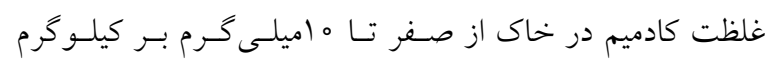

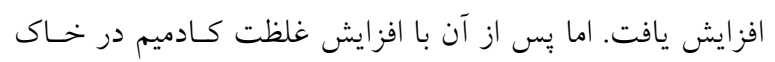

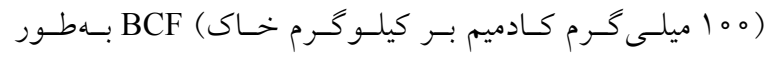

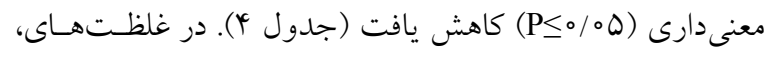

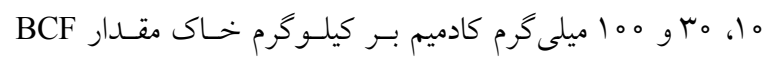

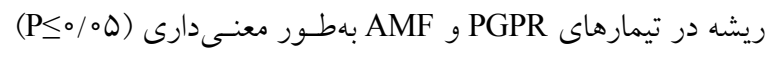

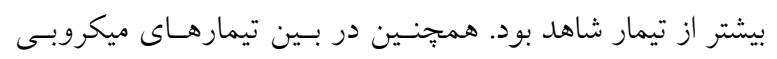

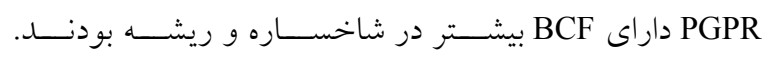
باطوركلى مايهزنى PGPR و AMF در تمامى سطوح كادميم در

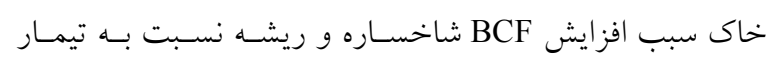

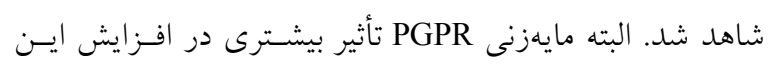

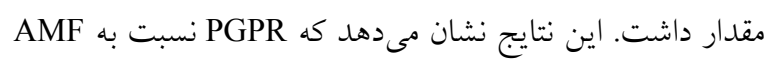

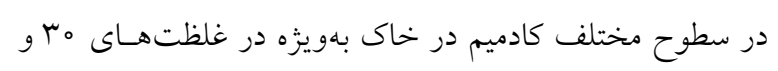

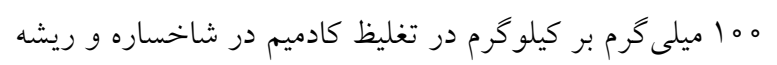

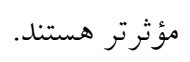

\section{فاكتور انتقال گياهى Translocation Factor (TF)}

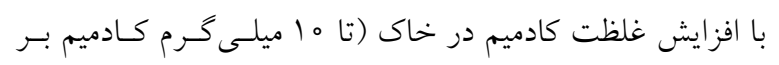
كيلو گرم خاك) مقدار فاكتور انتقال كيـاهى در تمـامى تيمـارهـا

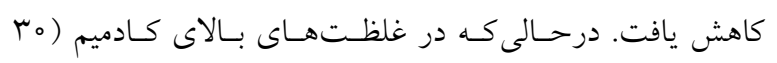

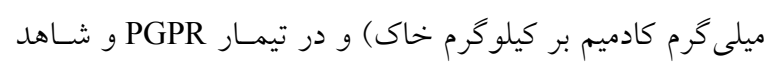

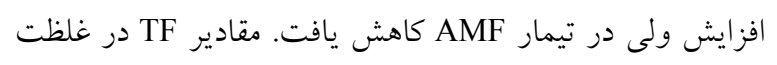

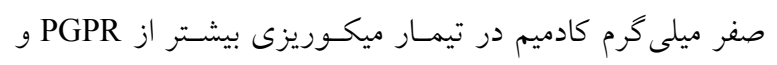

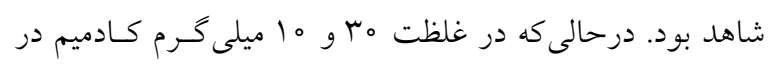
تيمار PGPR بيشـتر از ميكسوريزى و شـاهد بـود.
معنى دارى نسبت به كَاهانى كه آلودگى قـارج ريشـهاى ندارنسـ

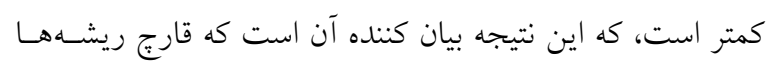

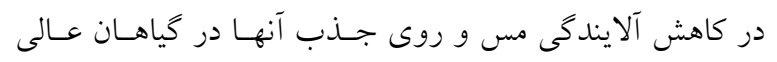

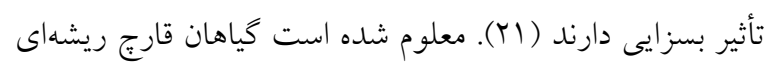

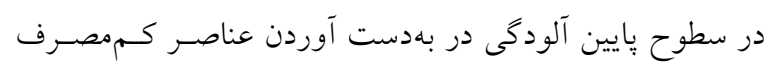

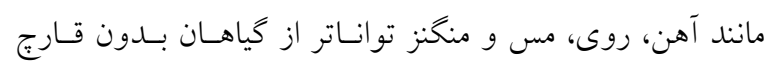

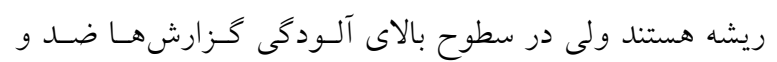

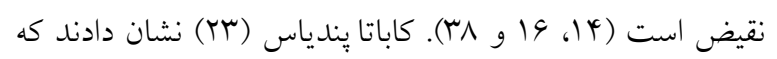

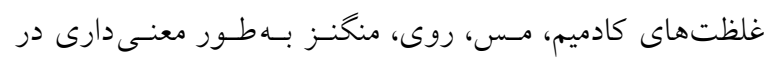

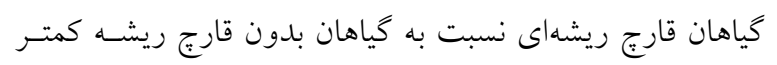

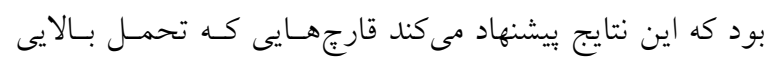

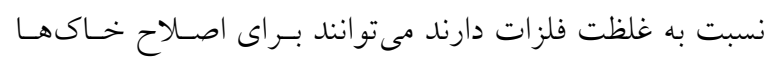

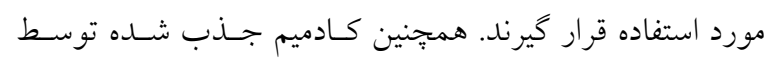

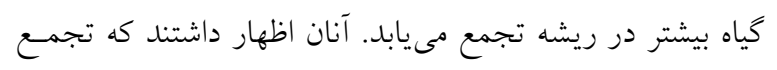

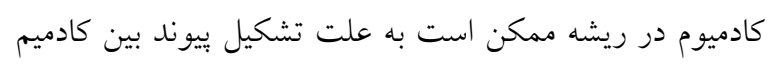
و سولفيدريل و يروتئينهايى به نام فيتولكتين باشد.

\section{غلظت كادميم در ريشه}

با افزايش غلظت كادميم در خاك، غلظت كـادميم در ريشـهـ در

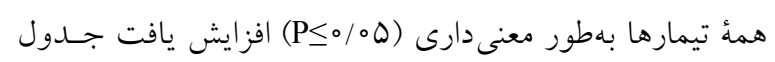

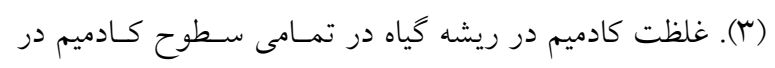

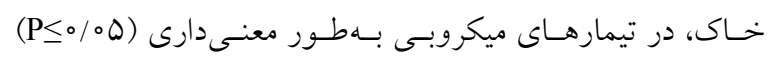

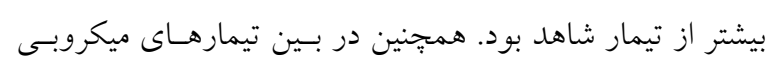

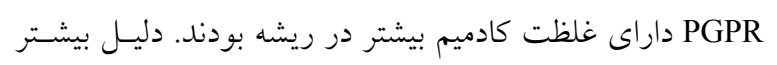

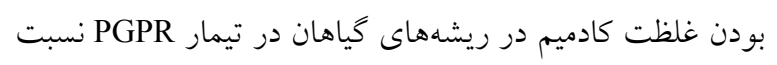

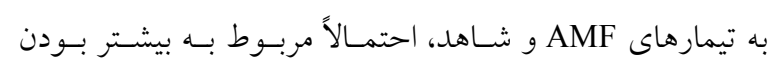

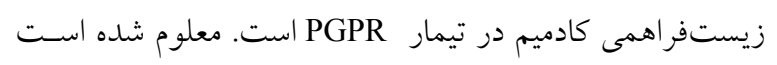

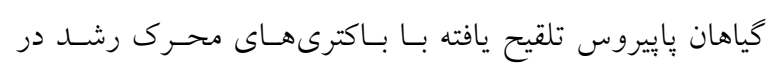

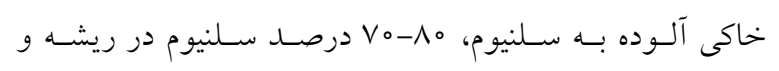

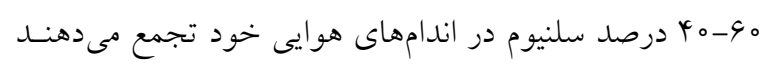

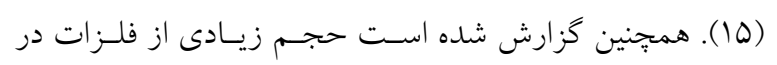

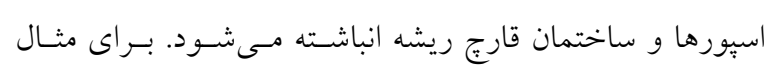


بررسى بتانسيل قارج ريشهها و باكترىهاى سودوموناس در بالايش سبز...

\begin{tabular}{|c|c|c|c|}
\hline \multicolumn{4}{|c|}{ در خاك در تيمارهاى شاهد، PGPR و AMF } \\
\hline AMF & PGPR & شاهد & كل كادميم افزوده شده به \\
\hline \multicolumn{3}{|c|}{ ضريب تغلظ زيستى (BCF) شاخساره } & خاى (mg kg-1 \\
\hline$\mu \circ / \Lambda \pm r / \circ b, b$ & $\mu_{\Lambda / \uparrow} \pm \circ / \uparrow^{\mathrm{a} a b c}$ & $\mu \psi / \mu \pm 0 / q^{a b, a b}$ & $\circ$ \\
\hline$q r / 9 \pm r / T^{a}, \mathrm{a}$ & $99 / \mathrm{V} \pm \mathrm{IV} / \mathrm{\mu}^{\mathrm{a}, \mathrm{a}}$ & $\leftarrow r / r \pm q / \Lambda^{\mathrm{baa}}$ & 10 \\
\hline$\Gamma_{0} / 9 \pm r / l^{b, b}$ & $\kappa r / l \pm \Delta / q^{a}, \mathrm{~b}$ & $r q / \Gamma^{\prime} \pm r / \Lambda^{\mathrm{b}, \mathrm{b}}$ & r。 \\
\hline $11 / 4 \pm 0 / \kappa^{\mathrm{b}, \mathrm{c}}$ & $19 / 1 \pm \circ / \Delta^{\mathrm{a}, \mathrm{c}}$ & $1 / \Lambda \pm \circ / Y^{c, c}$ & 100 \\
\hline \multicolumn{4}{|c|}{ ضريب تغليظ زيستى (BCF) ريشه } \\
\hline$\circ / \mathrm{QV}, \mathrm{d}$ & $1 / 0 \% b, d$ & $1 / I V^{a, d}$ & $\circ$ \\
\hline $9 / \mu r \mathrm{ba}$ & $V / 90_{0}^{a, a}$ & $r / q \gamma^{c, a}$ & 10 \\
\hline$r / q V^{b, b}$ & $r / q r^{a, b}$ & $r / / \psi_{c, b}$ & r。 \\
\hline $1 / \wedge \Delta^{b, c}$ & $r / 9 Y^{\mathrm{a}, \mathrm{c}}$ & $1 / \mu^{c}$ & 100 \\
\hline \multicolumn{4}{|c|}{ فاكتور انتقال كادميم (-) } \\
\hline$\Delta 1 / V Q^{\mathrm{a}, \mathrm{a}}$ & $r V / \Delta \Delta^{b, a}$ & $r q / \wedge^{c, a}$ & $\circ$ \\
\hline$৭ / 90 \mathrm{a}, \mathrm{b}$ & $\Lambda / q_{0} b, c$ & $\Lambda / V Q^{b, c}$ & 10 \\
\hline $\mathrm{V} / \Delta^{\mathrm{c}, \mathrm{c}}$ & $1 \circ / \wedge \Delta^{\mathrm{a}, \mathrm{b}}$ & $৭ / 9 b^{b, b}$ & r。 \\
\hline $\mathrm{d} / \Lambda^{\mathrm{b}, \mathrm{d}}$ & $9 / 9^{\mathrm{a}, \mathrm{d}}$ & $1 / 90 \mathrm{cld}$ & 100 \\
\hline
\end{tabular}

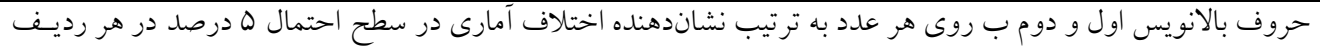

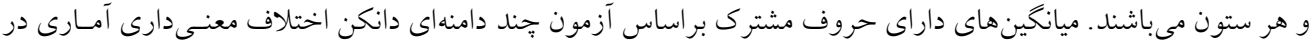

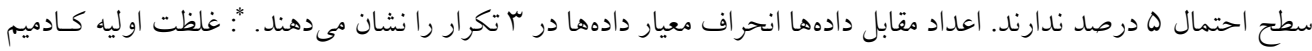

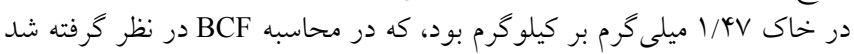

كاهش انتقال كادميم از ريشه به شاخساره (در غلظتهاى بالاى نتيجه كيرى نتيجه اين يزوهش نشان داد كه مايهزنى قـارج ريشـه AMF دري

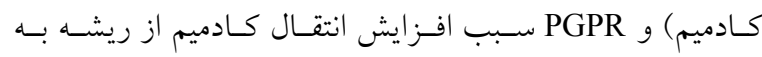

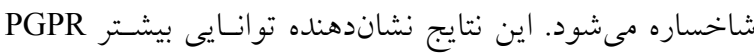

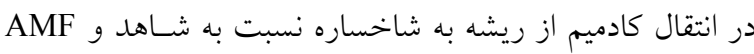
بود. جونر و ليوال (Yr) نشان دادند كه افزودن باكترى به محيط

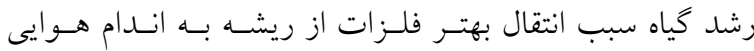

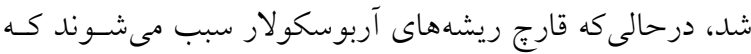

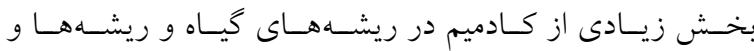

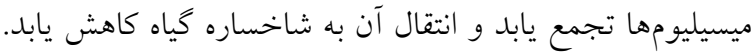

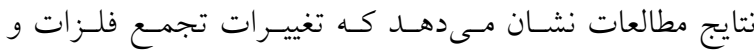

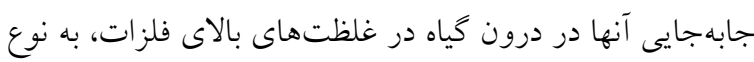

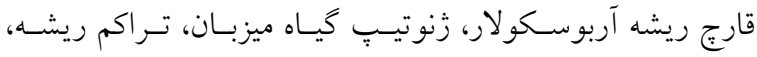

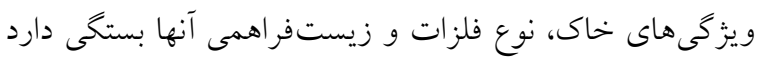

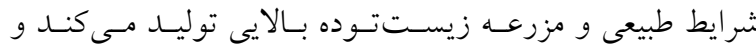

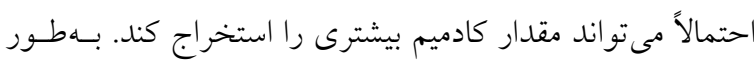




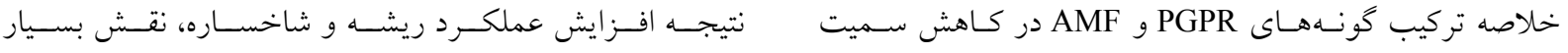

$$
\begin{aligned}
& \text { كادميم و افزايش آستانه تحمل كل كندم به سميت كادميم و در جشمخيرى در يّالايش سبز آلودگى كادميمى خواهند داشت. }
\end{aligned}
$$

$$
\begin{aligned}
& \text { منابع مورد استفاده }
\end{aligned}
$$

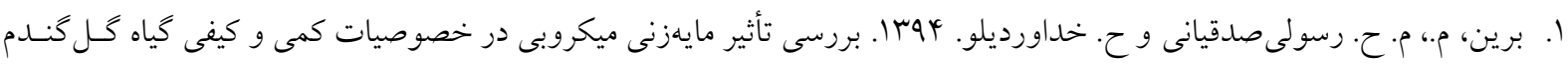

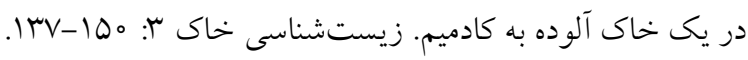

$$
\begin{aligned}
& \text { r. كاظم عليلو، س.، و م. ح· رسولى صدقيانى. rوبا. ارزيابى برخى شاخص هاى زيستى خاى در حضور ميكروار گانيسمهاى محرى }
\end{aligned}
$$

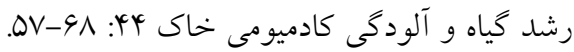

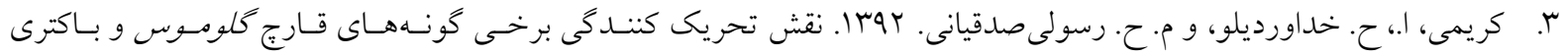

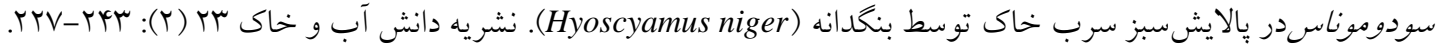

4. Abedi-Koupai, J. and A. H. Charkhabi. 2005. Phytoremediation of Petroleum Contaminated Soils, Aquifer Vulnerability and Risk, $2^{\text {nd }}$ International Workshop and 4th congress on the Protection and management of Groundwater. Italy, 21-23.

5. Abedi-Koupai, J. M., S. Vossoughi-Shavari, M. Yaghmaei and R. Ezzatian. 2007. Effects of microbial population on phytoremediation of petroleum contaminated soils using tall fescue. Int. J. Agric. Biol. 9: 242-246.

6. Abou-Shanab, R. A., J. S. Angle and R. L. Ghaney. 2006. Bacterial inoculants affecting nickel uptake by Alyssum murale from low, moderate and high Ni soils. Soil Biol. Biochem. 38: 2886-2889.

7. Arshad, M., M. Saleem and S. Hussain. 2007. Perspectives of bacterial ACC deaminase in phytoremediation. Trends Biotechnol. 25: 356-362.

8. Bates, L. S., S. P. Waldren and I. D. Teare. 1973. Rapid determination of free proline for water-stress studies. Plant Soil 39: 205-207.

9. Belimov, A. A., V. I. Sarfronova and T. Mimura. 2002. Response of spring rape to inoculation with plant growthpromoting rhizobacteria containing 1-aminocyclipropane-1-carboxylate deaminase depends on nutrient status of the plant. Can. J. Microbiol. 48: 189-199.

10. Blaudez, D., C. Jacob, K. Turnau, J. V. Colpaert, U. Ahonen-Jonnarth, R. Finlay, B. Botton and M Chalot. 2000. Differential reponses of ectomycorrhizal fungi to heavy metals in vitro. Mycol. Res. 104: 1366-1371.

11. Cariny, T. 1995. The Reuse of Contaminated Land: a Handbook of Risk Assessment. John Wiley and Sons Ltd. Publishers, England, UK.

12. Carter M. R. and Gregorich E. G. 2008. Soil Sampling and Methods of Analysis (2 ${ }^{\text {nd }}$ Ed.), CRC Press. Boca Raton, FL.

13. Chen, S. K., C. A. Edwards and S. Subler. 2001. Effects of the fungicides benomyl, captan, chlorothalonil on soil microbial activity and nitrogen dynamics in laboratory incubations. Soil Biol. Biochem. 33: 1971-1980.

14. Colpaert, J. V. and J. A. Van Assche. 1987. Heavy metal resistance in some ectomycorrhizal fungi. Funct. Ecol. 1: 415-421.

15. De Souza, M. P., C. P. Huang, N. Chee and N. Terry. 1999. Rhizosphere bacteria enhance the accumulation of selenium and mercury in wetland plants. Planta. 209 (2): 259-263.

16. Dehn, B. and H. Schuepp. 1989. Influence of VA mycorrhizae on the uptake and distribution of heavy metals in plants. Agric. Ecosyst. Environ. 29: 79-83.

17. Delauney, A. J. and D. P. Verma. 1993. Proline biosynthesis and osmoregulation in plants. Plant J. 4: 215-223.

18. Diaz, G., C. Azcon-Aguilar and M. Honrubia. 1996. Influence of arbuscular mycorrihza on heavy metal (Zn and $\mathrm{Pb}$ ) uptake and growth of Lygedum spartum and Anthyllis cytisoides. Plant Soil. 180: 241-249.

19. Giovannetti, M. and B. Mosse. 1980. An evaluation of techniques for measuring vesicular Arbuscular mycorrhizal infection in roots. New Phytol. 84: 489-500.

20. Gisbert, C., R. Ros, A. De Haro, D. J. Walker, M. P. Bernal, R. Serrano and J. A. Navarro-Avino. 2003. Plant genetically modified that accumulates $\mathrm{Pb}$ is specially promising for phytoremediation. Biochem. Biophys. Res. Commun. 5: 303-440.

21. Huang, Y., S. A. Tao and Y. J. Chen. 2005. The role of arbuscular mycorrhiza on change of heavy metal speciation in rhizosphere of maize in wastewater irrigated agriculture soil. J. Environ. Sci. 17(2): 276-280. 
22. Joner, E. J. and C. Leyval. 1997. Uptake of Cd by roots and hyphae of a Glomus mosseae/Trifolium subterraneum mycorrhiza from soil amended with high and low concentrations of cadmium. New Phytol. 135: 353-360.

23. Kabata-Pendias, A. and A. B. Mukherjee. 2007. Trace Elements from Soil to Human. Springer, Berlin, Germany.

24. Kaldorf, M., A. J. Kuhn, W. H. Schröder, U. Hildebrandt and H. Bothe. 1999. Selective element deposits in maize colonized by a heavy metal tolerance conferring arbuscular mycorrhizal fungus. J. Plant Physiol. 154: 718-728.

25. Khan, A. G. 2005. Role of soil microbes in the rhizospheres of plants growing on trace metal contaminated soils in phytoremediation. J. Trace Elem. Med. Biol. 1: 355-364

26. Khodaverdiloo, H. S. Ghorbani Dashtaki, and S. Rezapour. 2011. Lead and cadmium accumulation potential and toxicity threshold determined for land cress (Barbarea verna) and spinach (Spinacia oleracea L.). Int. J. Plant Prod. 5: 275-281.

27. Leyval, C., B. R. Singh and E. J. Joner. 1995. Occurrence and infectivity of arbuscular mycorrhizal fungi in some Norwegian soils influenced by heavy metals and soil properties. Water Air Soil Poll. 84: 203-216.

28. Leyval, C., K. Turnau and R. Haselwandter. 1997. Effect of heavy metal pollution on mycorrhizal colonization and function: physiological, ecological and applied aspects. Mycorrhiza 7: 139-153.

29. Liao, J. P., X. G. Lin, Z. H. Cao, Y. Q. Shi and M. H. Wong. 2003. Interactions between Arbuscular mycorrhizae and heavy metals under sand culture experiment. Chemosphere 50: 847-853.

30. Ma, Y., M. N. V. Prasad, M. Rajkumar and H. Freitas. 2011. Plant growth promoting rhizobacteria and endophytes accelerate phytoremediation of metalliferous soils. Biotechnol. Adv. 29: 248-258.

31. Malcova, R., J. Rydlova and M. Vosatka. 2003. Metal-free cultivation of Glomus sp. BEG 140 isolated from Mncontaminated soil reduces tolerance to Mn. Mycorrhiza 13: 151-157.

32. Marschner, H. and V. Romheld. 1995. Strategies of plants for acquisition of iron. Plant Soil. 165: 262-274.

33. McCue, K. F. and A. D. Hanson. 1990. Drought and salt tolerance: towards understanding and application. Trends Biotech. 8: 358-362.

34. McGrath, S. P., S. J. Dunham, and R. L. Correll. 2000. Potential for phytoextraction of zinc and cadmium from soils using hyperaccumulator plants. PP. 109-128. In: Terry N., S. G. Banuelos (Ed.), Phytoremediation of Contaminated Soil and Water. CRC Press, Boca Raton, FL.

35. Metwally, A., I. Finkemeier, M. George and K. J. Dietz. 2003. Salicylic acid alleviates the cadmium toxicity in barley seedlings. Plant Physiol. 132: 272-281.

36. Palutoglu, M., B. Akgul, V. Suyarko, M. Yakovenko, N. Kryuchenko and A. Sasmaz. 2018. Phytoremediation of cadmium by native plants grown on mining soil. Bulletin of Environmental Contamination and Toxicology. 100: 293-297.

37. Raskin, I., P. B. A. Nand-Kumar, S. Dushenkov and D. E. Salt. 1994. Bioconcentration of heavy metals by plants. Curr. Opin. Biotechnol. 5: 285-290.

38. Rudawska, M. and T. Leski. 1998. Aluminium tolerance of different Paxillus involutus Fr. strains originating from polluted and non-polluted sites. Acta Soci. Bot. Poloniae. 67: 115-122.

39. Salt, D. E., M. Blaylock, N. P. B. A. Kumar, V. Dushenkov, B. D. Ensley, I. Chet and I. Raskin. 1995. Phytoremediation: a novel strategy for the removal of toxic metals from the environment using plants. Nat. Biotechnol. 13: 468 - 474.

40. Shahabivand S., H. Z. Maivan, E. M. Goltapeh, M. Sharifi, A. A. Aliloo. 2012. The effects of root endophyte and arbuscular mycorrhizal fungi on growth and cadmium accumulation in wheat under cadmium toxicity. Plant Physiol. Biochem. 60: 53-58.

41. Verma, P., K. V. George, H. V. Singh and R. N. Singh. 2007. Modeling cadmium accumulation in radish, carrot, spinach and cabbage. Appl. Math. Model. 31: 1652-1661.

42. Zhang, H. H., M. Tang and C. Zheng. 2010. Effect of inoculation with AM fungi on lead uptake, translocation and stress alleviation of Zea mays L. seedlings planting in soil with increasing lead concentrations. Eur. J. Soil Biol. 46: 306-311. 


\title{
Evaluation of the Potential of Soil Microbial Activity on Cd Phytoremediation in a Contaminated Soil
}

\author{
M. H. Rasouli Sadaghiani ${ }^{*}$, H. Khodaverdiloo, M. Barin and S. Kazemalilou ${ }^{1}$
}

(Received: Sept. 28-2014; Accepted: Feb. 28-2018)

\begin{abstract}
The use of plants and soil microorganisms is a promising technique for the phytoremediation of heavy metalcontaminated soils. This study was carried out in order to evaluate the soil microbial potential with four Cd concentration levels $(0,10,30$ and $100 \mathrm{mg} \mathrm{kg}-1)$; the study also addressed the inoculation of arbuscular mycorrhizal fungi (AMF) species (a mixture of Glomus species including G. intraradices, G. mosseae and G. fasciculatum) as well as plant growth promoting rhizobacteria (PGPR) (a mixture of Pseudomonas species including P. putida, P. fluorescens, and P. aeruginosa) with the Centaurea cyanus plant. The soil sample was spiked uniformly with Cd nitrate salt to create different $\mathrm{Cd}$ concentrations. The contaminated soils were then sterilized and subsequently inoculated with AMF and PGPR. The results indicated that with increasing the soil $\mathrm{Cd}$ concentration, colonization percent, abundance of rhizobateria, shoot biomass, and shoot relative biomass were significantly decreased, while the proline content and the shoot $\mathrm{Cd}$ concentration were significantly increased $(\mathrm{P} \leq 0.05)$. The mean of $\mathrm{Cd}$ extracted in AMF and PGPR treatments was 1.8 and 2.8 and the translocation factor was 1.2 and 1.5 times higher, as compared to the corresponding control treatments, respectively. It could be concluded that microbial inoculation, in addition to improving plant growth, plays an important role in the Cd phytoremediation efficiency by plant.
\end{abstract}

Keywords: Phytoremediation, Centaurea cyanus, Cd, Arbuscular mycorrhizal fungi, Plant growth promoting rhizobacteria.

1. Dept. of Soil Sci., Faculty of Agric., Urmia Univ., Urmia, Iran.

*: Corresponding Author, Email: m.rsadaghiani@urmia.ac.ir 